BULLETIN Bulletin hispanique

HISPANIQUE Université Michel de Montaigne Bordeaux

$110-2 \mid 2008$

Varia

\title{
Genoveva de Brabante
}

génesis del personaje y su lugar en la historia de la edición

\section{Magdalena Maurici Frades}

\section{(2) OpenEdition}

Journals

Édition électronique

URL : http://journals.openedition.org/bulletinhispanique/793

DOI : $10.4000 /$ bulletinhispanique.793

ISSN : $1775-3821$

Éditeur

Presses universitaires de Bordeaux

\section{Édition imprimée}

Date de publication : 1 décembre 2008

Pagination : $573-600$

ISBN : 978-2-86781-543-0

ISSN : 0007-4640

Référence électronique

Magdalena Maurici Frades, «Genoveva de Brabante », Bulletin hispanique [En ligne], 110-2 | 2008, mis en ligne le 01 décembre 2008, consulté le 10 décembre 2020. URL : http://journals.openedition.org/ bulletinhispanique/793 ; DOI : https://doi.org/10.4000/bulletinhispanique.793 


\title{
Genoveva de Brabante, génesis del personaje y su lugar en la historia de la edición
}

\author{
Magdalena Maurici Frades \\ Universitat de Barcelona
}

Dans le cadre de la tradition orale, au cours du Moyen Âge, ont été créées des "histoires" qui trouvèrent par la suite leur place dans la littérature imprimée. Ainsi l'Histoire de Geneviève de Brabant est une narration aux nombreuses facettes, qui sont reprises d'autres "histoires". Les éditions, française et espagnole, de ce texte montrent des différences de style notables. On analyse la trajectoire éditoriale de cette ouvre dans le contexte hispanique.

De la tradición oral, y a lo largo de la Edad Media, van creándose unas "historias" que encuentran lugar en la producción impresa. Asi, la Historia de Genoveva de Brabante es una narración llena de facetas, ya vistas en otras "historias". Las ediciones, francesa y española, evidenciarán las diferencias de estilo notables. Finalmente, se analiza la trayectoria editorial de esta obra en el contexto hispánico.

During the middle Ages, "stories" were built up within the framework of oral tradition and were later incorporated into the printed literature. 'The Story of Genevieve de Brabant', for instance, is a multifaceted narration, picking its material from other "stories». The French and Spanish editions of this text offer notable stylistic differences. I will therefore analyze the editorial trajectory of this work within a Hispanic context.

Mots-clés : Moyen Âge - Geneviève de Brabant - Genèse du personnage Éditions - Espagne - France.

$B H i$, Tome $110, \mathrm{n}^{\circ} 2$ - décembre 2008 - p. 573 à 600. 


\section{La formación de un arquetipo femenino literario}

UANDo nace la imprenta, el negocio editorial se dispone a complacer a de historias, cuentecillos tradicionales se habían divulgado enormemente. Las prensas europeas (centros impresores como Lyon o Venecia) habían demostrado su quehacer en la elaboración de textos griegos y latinos destinados al estudio. Pero aún quedaba una tarea más ardua pero que prometía unos resultados económicos de lo más halagüeño; los impresores vieron en esa producción varia, antes aludida, formada por narraciones de diverso origen (tradicional, folklórico) una cantera para llevar a cabo una producción impresa que, en un primer momento, se caracterizó por seguir los caminos ordinarios de cualquier edición; es decir, con una encuadernación, que, algunas veces, era de lo más lujoso ${ }^{1}$, como corresponde a ediciones del siglo XVI. Pero con el tiempo eso varió, los impresores vieron amplias posibilidades en encontrar nuevos formatos que abaratasen considerablemente el coste de las ediciones; de ahí, que en la Europa moderna apareciesen formatos que son ejemplo de ello: desde los pliegos sueltos (tanto españoles como italianos) hasta llegar a la producción de la Bibliothèque bleue. Producción impresa, esta última, consagrada a divulgar desde los ciclos de antiguos cantares de gesta (como el propio ciclo carolingio) a los que desde los tiempos de la edición manuscrita se habían ido ańadiendo fragmentos de distinta naturaleza oral: fragmentos de otros cantares prosificados, y asimismo cuentecillos tradicionales y leyendas de origen folklórico ${ }^{2}$.

1. Cabe comprobar eso último en una edición de La Reina Sebilla de 1585, que se halla en la Biblioteca de Catalunya, a cargo de Pedro López de Haro, en Toledo. 4o 36 fols. Signaturas a-c 8, d 12 [...] Tip. Góts. Dos tomos; bellamente encuadernada, y que refleja aún ciertos vestigios medievales, por ejemplo el que se conserve la foliación (Millares Carlo, Agustín, Introducción a la ha del libro y de las bibliotecas. México, FCE, 1971). Si bien es cierto, como afirma Nieves Baranda, en su edición y prólogo de las Historias caballerescas del siglo XVI, Turner, Biblioteca Castro, 1995, 2 vols, p. XXXVII, que La Historia de la Reina Sebilla sufre una evolución respecto de las demás; así en el quehacer editorial se viven ciertos cambios originados ante la idea de adaptarse a los nuevos tiempos, y así en la edición de 1532 se incluyen divisiones por capítulos y en éstos las rúbricas correspondientes que no tenían la edición de c. 1500. ¿Qué evidencia? Que en un principio esas ediciones se supieron acoplar a los nuevos tiempos, pero conservaban antiguos recursos, sufijos arcaicos verbales. Dice el texto: «-No vos acuitedes que no [...]», Nieves Baranda, op. cit., p. 436. Y en el mismo texto suelen aparecer fragmentos de los cantares de gesta: "pesóle de coraçon muy mucho [...]», op. cit. p. 437.

2. Ramón Menéndez Pidal fue quien, a través de una vasta y larga obra dedicada al estudio del origen de la poesía épica de la Romania, aportó con una serie de ejemplos irrefutables la teoría, el Cantar de Roldán y el neotradicionalismo, mediante la cual demostraba el transcurrir 
Aunque, alguna que otra vez, se suele citar la procedencia de la tradición oral, siempre suele darse de una manera tangencial. Existe un recelo evidente, un prejuicio en aceptar la importancia de la cultura oral. Así, Nieves Baranda $^{3}$ afirma cuando habla de las características de La Reina Sebilla, perteneciente al ciclo carolingio: «Estos rasgos presentes en todas ellas quizá estén relacionados con su difusión oral a través de la lectura en voz alta que necesita mecanismos de recuerdo y claridad distintos de los que esperamos hoy en día como lectores bien entrenados.»

Sería esa una forma fácil de acabar con la cuestión, pero el bosque resulta ser mucho más intrincado. Precisamente, La Reina Sebilla, fiel herencia de un manuscrito, Cuento del emperador Carlos Maynes e de la Emperatriz Senilla ${ }^{4}$, reproduce las técnicas del llamado estilo oral. Si bien cabe decir que la propia edición de La Reina Sebilla contenga los logros de la escritura, como es el hecho de que se puntúe. Pero no por ese motivo se abandona totalmente el estilo oral; así suele darse la aparición del narrador en $1^{a}$ persona "hablando» a sus interlocutores 5 . Sin duda la transmisión juglaresca aún se hallaba presente.

Esas «historias", Berthe aux grands pieds, La Reina Sebilla y nuestra Geneviève de Brabant, no se improvisaron; autores de los que nunca se supo su nombre (tiempo más tarde, aparecieron autores, pero una vez que tales «historias» se habían incorporado en la mente de las gentes), juglares, primero, quizá, y luego más tarde los primeros editores de la producción manuscrita que reprodujeron el arquetipo femenino de una sociedad patriarcal donde la mujer, fiel guardián de un linaje, no podía incurrir en ningún tipo de falta. De ahí, entonces, que ciertos «aspectos» se repitiesen continuamente en el momento de irse creando la narración. Formaron un «fondo común» del que se surtían quienes se hallaban interesados en la creación literaria. La procedencia de esos «aspectos» era indiscutiblemente tradicional, de vía oral.

y propagación de una poesía épica a lo largo de la Edad Media, por los juglares, cuyo quehacer generó toda una literatura europea.

3. Op. cit. p. XXXVII.

4. «[...] Códice en folio mayor, escrito en pergamino, a dos columnas, fines del siglo XIV o principios del XV, y señalado con el título Flos Sanctorum», Marcelino Menéndez Pelayo, Antología de poetas líricos castellanos. C.S.I.C., Santander, 12 vols; vol. VII, p. 245.

5. Cotejando los dos textos (el manuscrito y el impreso, hallamos el narrador en el texto manuscrito del Cuento del enperador Carlos Maynes e de la Emperatriz Seuilla: «[...] mas agora ascuchat que fue a pensar el traidor del enano, que Dios destruya, que nunca otra tal traición basteçio un solo omne,[...]». Y el propio texto impreso reproduciendo el mismo pasaje: «[...] mas agora escuchat que fue a pensar el traidor del enano, [...]», repitiéndose la misma interpelación que hace el narrador en el texto manuscrito: «Agora oyd que fue a pensar el traydor del enano $[\ldots] »$. 
De ahí, que Thompson estudiase esos «aspectos» en la materia folklórica, a los que llamó «motivos». En un estudio dedicado a Boccaccio y los folkloristas ${ }^{6}$, aparece la definición que da Thompson de lo que se entiende por «motivo»: "on s'attendrait plutôt à ce que soient appelées motifs, les situations concrètes dans lesquelles peut s'incarner un même thème». Un mismo "tema» que iría repitiéndose como génesis de tantísimas historias.

Tal es el caso que nos ocupa en las presentes líneas, Genoveva de Brabante, narración de la que hacen constancia un buen número de catálogos sobre impresos de la Edad Moderna. Gozó de una enorme difusión. En principio, la leyenda cuenta como Geneviève de Brabant o Genoveva de Brabante se halla casada con el príncipe del Palatinado, Sigfrido de Trèves. Alejado, este último, de sus tierras en ayuda de las tropas de Carlos $\mathrm{Martel}^{7}$, que se halla en el intento de ganar Narbonne a los sarracenos, deja a su esposa, Genoveva, bajo los cuidados de su mayordomo Golo. Éste, desleal a su señor, se dedica a cortejar a Genoveva; Golo, al sentirse despreciado por la condesa, urde una horrible venganza: desembarazarse de Genoveva y del hijo que acaba de dar a luz. Para tal cometido manda a dos criados para que ejecuten la abominable acción de matar a Genoveva y a su hijo. Los dos criados se compadecen de su infeliz señora, y así le perdonan la vida, y del mismo modo, como el perverso Golo ha pedido que se le muestre la lengua de la infeliz víctima, traman presentarle la lengua de un perro, en vez de la de Genoveva, como había exigido el traidor Golo. Sigfrido recibe las nuevas de la infidelidad de su esposa y de su posterior castigo. La tristeza invade el ánimo del marido. Transcurridos seis años, el conde sigue en una cacería a una gacela que resulta ser la que ha amamantado al hijo de Genoveva. En su carrera, el conde Sigfrido encuentra finalmente a su esposa e hijo. Se castiga finalmente al traidor Golo. Finaliza la narración con la muerte de Genoveva, a la que se venera como si fuese una santa. La gruta en la que vivió tantos ańos recluida se convierte en un santuario, de la que se convierten en sus fieles guardianes su marido e hijo.

6. Albert Beaudoux-Spinette, "Boccace et les folkloristes», in Boccaccio nelle culture e letterature nazionali. Firenze, Leo S. Olschki, 1978, pp. 621 y ss. Aparte está la obra capital de Thompson, Stith, Motif-Index of Fol.-Literature. A Classificattion of Narrative Elements in Folktales, Ballads, Myths, Fables, Mediaeval Romances, Exempla, Fabliaux, Jest-Books, and Local Legends, 6 Bloomington y Londres, Indiana University Press, 1966.

7. Esto último se añadirá en la edición llevada a cabo por el padre Cerisiers en la Bibliothèque bleue con el nombre de L'innocence reconnue. 
Como en toda historia que recoge la Bibliothèque Bleue, en Geneviève de Brabant o Genoveva de Brabante ${ }^{8}$ aparecen elementos de tipo tradicional. Entonces, la «historia» no es nueva, diferentes «motivos» fueron hilvanando, configurando la «historia».

\section{I.1 Los motivos engarzan una «historia». El personaje de Geneviève aparece pintado con «colores» ya conocidos}

Como si de una paleta imaginaria se tratara, el "pintor» en este caso, va eligiendo colores con los que vestir a sus personajes. Podría decirse que el atuendo o vestidos del personaje no son nada nuevos. El lector avispado descubre elementos que ya se han ido creando en otros personajes.

Primer motivo: La configuración del personaje. El perfil psicológico de Geneviève de Brabant aparece ya definido en la propia historia de la propia Griséledis o Griselda ${ }^{9}$, Grisélédis ${ }^{10}$ o también llamada Griselda. Prueba de enorme obediencia y sumisión al marido llegando a casos de verdadero paroxismo y enajenación; como el de exigir la muerte de la hija porque no

8. Las citas de Geneviève de Brabant proceden de la edición, La Bibliothèque Bleue. La littérature populaire en France du XVII au XIX $X^{e}$ siècle. Paris, Julliard-Gallimard, coll. Archives, 1971, 274 p. (2a ed. 1980).

9. Ya en el Decameron de Boccaccio se inserta en la Giornata decima, la Novella decima, la «historia» «da il marchese di Saluzzo [...]». En el presente texto se alude a la edición italiana, Giovanni Boccaccio, Decameron. A cura di Vittorio Branca. Milano, Mondadori Edittore S.p. A. Oscar classici, 146, 2 vols., 1989. Asimismo, en el siglo XV, Christine de Pisan incluye la historia de Griselda en su obra La cité des dames, Paris, Sock / Moyen Âge, 1986, p. 196. Contó con un buen número de ediciones. Una $1^{a}$ edición francesa, traducida del latín, de la obra de Petrarca: La patience griselidis Marquis de Saluces..., París, 1510? 4º. Una 2a edición francesa en verso, La Mystere de Griselidis marquis de saluses par personnaiges. Editado por G. Y V. Giraud y A. Veinant, París, 1550 ? Reimpresión, 4º. Una $3^{\text {a }}$ edición italiana, Historia celeberrima di Gualtieri, Marquis de Salazzo, il quale elesso di maritarsi in Griselda, etc, 1525? $4^{\circ}$. Quedarían por citar varias ediciones inglesas que tuvieron lugar en el inicio de la imprenta, entre los años de 1600 y 1690. British Museum Catalogue of Printed Books, London, 19311966, pp. 719-720.

10. De entrada, la historia de Grisélédis contiene una serie de elementos que anunciaba su futuro éxito, una especie de «manual» de la perfecta casada, tan acorde con la mentalidad de la época. Una mujer, Griselda, de origen humilde, se casa con el marqués de Saluces, quien impone a su mujer una serie de pruebas humillantes para comprobar su sumisión. Tanto el personaje de Griselda como el de su marido van sufriendo variaciones a lo largo del tiempo. El relato gozó de un gran número de ediciones, por lo tanto la trayectoria de Grisélédis conllevó necesariamente cambios, como el enfoque que le confirió la autora francesa del siglo XIV, Christine de Pisan, en su célebre obra La cité des femmes, de valorar la fuerza de carácter del personaje femenino en una situación adversa. 
le complace que sea su heredera; o bien cuando pretende repudiarla, y así aparentemente lo lleva a cabo. Griselda debe abandonar su hogar y volver a la pobreza de su origen. Todo ello nuestra protagonista lo sufre y lo acepta sin poner ningún reparo. He ahí, pues, la primera "pincelada» que va a configurar a Geneviève:

Muchacha, oculta a las miradas de los demás, presenta una personalidad basada en la sencillez y en la humildad. A este tenor, dice el texto de Geneviève de Brabant: "[...] que la Perle n'est point si précieuse dehors que dedans san nacre, $\&[\ldots] »^{11}$. Huir de toda ostentación. Humildad, y sometimiento al futuro marido. El futuro marido siempre es superior a nuestro personaje femenino, así dice: "Ma noblesse n’est pas égale à la vôtre; je sais néanmoins qu'elle ne vous peut être honteuse, si vous me faites l'honneur d'en agréer l'alliance. La fortune ne m'a pas donné si peu de biens que je ne puisse soutenir la dignité de votre illustre Maison» ${ }^{12}$. La propia Griselda se enfada si alguien habla mal del marido: "[...], che ella fece ragionare del suo valore el del tuo bene adoperare, $e$ in contrario "rivolgere", se alcuna cosa detta s'era contro al marito per lei quando sporata l'avea» ${ }^{13}$. Y del mismo modo Geneviève manifestará también inmensa alegría por entablar parentesco con la familia del marido: «il remercia -dice la edición francesa-Sifroy d'avoir jetté les yeux sur elle» ${ }^{14}$.

Berthe aux grands pieds, La Reina Sebilla, como Geneviève de Brabant van a ser el polo opuesto de otra concepción de mujer: Ghismunda, que aparece en el Decameron de Boccaccio, en la giornata IV, novella $1^{15}$ : ni docilidad, ni obediencia, sino rienda suelta a las emociones y a las pasiones sin freno. Hija del príncipe Tancredo de Salerno mantiene una relación amorosa con un criado, llamado Guiscardo. Doble falta: como mujer, dejar libres sus instintos, y luego, el amante es de baja condición social. Al conocer Tancredo las relaciones ilícitas que mantiene su hija con un sirviente, manda encarcelar al criado y lo condena a muerte. El último gesto de crueldad es ofrecerle a su hija en una copa el corazón de su amante. Presa por el dolor, Ghismunda se quita la vida. El padre, arrepentido, los entierra en una misma sepultura.

Segundo motivo: la figura del traidor. Como ya se ha visto, el personaje femenino no presenta ningún tipo de mácula, ni mancha; tendrá su contrapartida en el personaje maligno, quien va a ser digno representante

11. Linnocence reconnue, op. cit., p. 245.

12. Ibidem, p. 247.

13. G. Boccaccio, Decameron, op. cit., p. 896.

14. Linnocence reconnue, op. cit., p. 247.

15. G. Boccaccio, Decameron, op. cit., pp. 336-348. 
del mal: el traidor Golo, culpable de las tragedias que van a desencadenarse en la «historia». En La reina Sebilla aparece asimismo la figura de un traidor, Macaire: «[...]. El enano era la más fea cosa del mundo, que era negro y la catadura muy fea y muy mala, y los ojos pequeños, engordidos, y los braços gordos, y la cabeça grande, y las narices gordas y muy anchas, y las orejas grandes, y los cabellos crespos, y los braços y las piernas vellosas como osso, $[\ldots]{ }^{16}$. El horrible aspecto de Macaire coincide con las intenciones de Golo, que ofenden en grado sumo a Geneviève al comprobar que intenta seducirla a toda costa. Tanto en el caso de la La reina Sebilla como en el de Geneviève o Genoveva de Brabante, los «traidores» falsean la realidad para vengarse de la negativa a sus propósitos amorosos o bien idean situaciones para que el personaje femenino no pueda hacer valer su inocencia. Eso último es lo que ocurre en La reina Sebilla, cuando Macaire se esconde en la propia cama de la reina: «[...]. Y alçó el rico cobertor y metióse debaxo. [...] que vino el rey con sus cavalleros [...], y alçó el rico paramento o cobertor con que estava cobijada, y vido el enano que yazía cerca della.» ${ }^{17}$. El rey monta en cólera al sentirse engañado. En el caso de Geneviève o Genoveva de Brabante, el traidor Golo urde una falsa relación entre la condesa y el «cuisinier» de palacio:

\begin{abstract}
Il y avoit un cuisinier à la Maison qui avoit gagné les bonnes grâces de la Comtesse par sa vertu, c'étoit-là le seul artifice \& la Magie dont il falloit user pour en posséder le coeur \& l'affection. L'Intendant l'ayant reconnu avec les autres domestiques, se résolut de faire encore une fois ses honteuses demandes, ơ au cas qu'il fût refusé, rendre la chasteté de Geneviève suspecte à celui qui n'en devoit pas douter: sa grossesse servoit de prétexte à sa malice, \& l'envie que les autres Serviteurs portoient à ce pauvre cuisinier, promettoit une facile créance à sa calomnie ${ }^{18}$.
\end{abstract}

De ese modo, la infeliz Geneviève cae en una trampa que va a depararle solamente desgracias.

Tercer motivo: El bosque, el lugar del suplicio. Un motivo que se repite en toda la Romania. Golo manda a sus criados para que acaben con la infeliz Geneviève y su hijo en el bosque. El «bosque» es el lugar elegido por la pérfida ama de llaves, cuya hija suplanta a Berta, la de los grandes pies, la madre

16. Historia de la reina Sebilla en Historias caballerescas del siglo XVI, edición y prólogo de Nieves Baranda. Vol. I, p. 419, op. cit.

17. Op. cit., p. 422.

18. L'innocence reconnue, op. cit., p. 263. 
de Carlomagno ${ }^{19}$. En este tercer motivo, se añade la piedad y compasión de los verdugos hacia sus víctimas, lo que motivará que las «historias» de esos personajes femeninos varíe por completo. Los crueles traidores exigen siempre una prueba, la lengua de la infeliz víctima: «[...]. Et pour avoir quelque marque de leur cruelle obéissance, il voulut quils lui apportassent la langue de cette méchante femme, c'est ainsi quil appelloit cette innocente Princesse.» ${ }^{20}$. En el caso de la "historia» de Geneviève, los criados sacrifican a un perro cuya lengua calmará la venganza del cruel Golo. En el caso de Berthe, la de los grandes pies, los criados, para hacer creíble la "historia» de la muerte de la reina, entregan a la cruel ama el corazón de un perro ${ }^{21}$. Esa coincidencia no debe extrañar, el propio Menéndez y Pelayo lo había expuesto en su obra, Antología de poetas líricos castellanos ${ }^{22}$ cuando cita el mismo motivo que aparece en la "historia" de Berthe, aux grands pieds, y en el romance carolingio de Gaiferos. El famoso ardid de que se valen los dos lacayos de Galván -el cruel enemigo del niño Gaiferos-, el ardid o artimaña consiste en presentar el corazón de una perrita y uno de los dedos del niño Gaiferos para mostrar la veracidad de su muerte. Gaiferos, personaje histórico, señor de Aquitania, luchó de forma enconada contra Pipino, el padre de Carlomagno. La leyenda lo acercó a los Pares de Francia y a la mismísima corte de Carlomagno; su mujer Melisendra, al parecer hija de Carlomagno, es fruto asimismo de la leyenda.

Y un cuarto motivo: el del anillo y los peces, que ayuda a que la «historia» vaya enlazando con elementos que se habían citado al principio de la narración.

19. Una de las ediciones impresas que se conocen de La gran conquista de Ultramar, la que menciona Adolfo Bonilla en su prólogo a la Historia de Flores y Blancaflor (Madrid, 1916), una edición salmantina de 1503, contiene varios pasajes de los distintos manuscritos que vivió la historia caballeresca, entre ellos el que se refiere a la madre de Carlomagno, Berta, la de los grandes pies, y al Sainete, la juventud de Carlomagno, pero a decir de Rodríguez Velasco (1997: 342): «[...], podemos observar que los componentes salmantinos introdujeron notables cambios. [...] Los cambios son, aparte de supresiones y correcciones, aparte de modernizaciones y cambios lingüísticos, algunas interpolaciones que afectan a las modas narrativas y expresivas de 1503.»

20. L innocence reconnue, op. cit., p. 276.

21. La "historia» de Berthe sigue con un sinfín de sucesos: un montonero del rey, que vive en el bosque, descubre a la infeliz Berthe y la acoge en su casa como una hija más. El rey Pipino, que no nota la diferencia del cambio con la hija del ama, llega a la casa del montonero un día de caza y se siente atraído por la que cree ser una sencilla plebeya sin sospechar que es su verdadera esposa. Yace con ella esa misma noche, naciendo más tarde Carlos, el futuro Carlomagno.

22. Marcelino Menéndez y Pelayo, Antología de poetas líricos castellanos. CSIC, Santander, 1944, vol. VII, pp. 62-63. 
En Geneviève de Brabant, se trata del hallazgo del anillo que la protagonista ha arrojado al río Mosela: gracias al regalo de un pescador, encuentra en el buche de un pez el anillo ansiado, lo que le ocasiona una enorme alegría.

Pero no así en La Historia de Pierres de Provenza y la linda Magalona, donde la pérdida, esta vez de tres anillos, comporta la desesperación y una honda amargura, después de haber vivido los dos personajes protagonistas una serie de aventuras, puesto que se ven obligados a abandonar las posesiones de Magalona por no permitir los padres el enlace matrimonial con Pierres. En un momento de descuido, un ave rapaz arrebata la bolsa que contiene los tres anillos. Pierres, desesperado, irá en su búsqueda. Los tres anillos no vuelven a aparecer hasta que los padres de Pierres se hacen con un pez que contiene la bolsa y los tres anillos: desespero de los padres de Pierres, por creerlo muerto, y pena profunda por parte de Magalona que aún no ha desvelado su identidad. La narración de la Historia de Pierres de Provenza y la linda Magalona forma parte asimismo de la Bibliothèque bleue $e^{23}$.

Esos cuatro «motivos» de origen tradicional que, como se ha podido comprobar, se habían dado en toda la Romania, configuran al personaje de Geneviève de Brabante ${ }^{24}$.

\section{2 Reflexión última: otros aspectos que añadir a la configuración del personaje de Genoveva}

En todo momento se tendrán en cuenta dos ediciones: la francesa, que se ha estado trabajando anteriormente, y la traducción al castellano, llevada a

23. Aunque la Historia de Pierre de Provenza y de la linda Magalona tuvo unos inicios editoriales mucho más ricos. Los impresores vieron tiempo más tarde un verdadero filón en la producción editorial de la Bibliothèque Bleue, y así aparecieron las siguientes ediciones:

L'Histoire de Pierre de Provence et de la belle Maguelonne, Troyes, vendiéndose en París, en la casa de A. Rafflé, ¿16 --? En The Nacional Union Catalog Pre-Imprints 1956, vol. 458, p. 20.

Por los datos que aporta el catálogo estadounidense, todo hace suponer que la presente edición, por el número de páginas -64-, no formaba parte de la Bibliothèque Bleue. Por otra parte, nuestro relato va siguiendo los pormenores de la historia del libro: en el siglo XVII no produce extrañeza que la edición posea título.

También aparece nuestra narración unida a otra «historia», Jean de Calais. L'histoire de Pierre de Provence \& de la belle Maguelonne, Rouen, D. Ferrand, ¿163-?, in 4º 48 páginas. El relato aparece unido a otra "historia» de la Bibliothèque Bleue, Jean de Calais en The Nacional Union Catalog Pre-1956 Imprints, vol. 458, p. 20.

24. Vida de Santa Genoveva, princesa de Brabante: traducida al español por el padre Cerisiers. Madrid, Antonio Pérez de Soto; a costa de D. Pedro Joseph y Padilla..., 1760. 200 p.; $8^{\circ}, 14 \mathrm{~cm}$. 
cabo por el mismo adaptador de la edición francesa de Geneviève de Brabant, René de Ceriziers (1603-1662), en 1760, con el título de Vida de Santa Genoveva, princesa de Brabante.

Geneviève de Brabant recibe castigo por adulterio. Ha infringido una de las normas sagradas del sistema patriarcal. El adulterio, ejercido por la mujer, tenía y aún posee un estigma: pone en duda el propio linaje ${ }^{25}$. El varón, ante el mismo hecho, no recibe ningún tipo de castigo. En todo caso amonestación, pero siempre se encontrarán atenuantes para entender una determinada postura masculina; en la mujer no habrá perdón, ridiculiza la estirpe del propio marido. Geneviève debe recibir castigo. Sifroy recibe las nuevas de su mujer pero en ningún momento se compadece de ella. El pecado debe ser expiado. Aunque luego resultará que es inocente.

Geneviève de Brabant representará el «canon» que debe observar toda mujer, como se ha dicho antes. En definitiva, el perfil del personaje quedaría enmarcado por dos factores: paciencia y conformidad. Dos virtudes, diríamos, cristianas. De hecho, a lo largo de toda la narración es invocada la "Providencia»: "J'entends bien, mon cher Lecteur, que tu demandes, s'il y a une Providence qui veille sur les desseins des hommes [...]; que si Dieu semble quelquefois sommeiller au milieu de nos misères, c'est afin de nous sauver avec plus de merveilles, [...]» ${ }^{26}$.

"Conformidad» ante la nueva situación de miseria en la que se halla la infeliz Geneviève: "[...]. N'étoit-ce pas un spectacle digne de compassion de voir la ferme d'un Palatin dans le défaut de toutes choses? Son Palais changé en une offreuse solitude, sa chambre en une grotte effroyable, ses courtisans en bêtes farouches, sa musique aux hurlements des loups, ses viandes délicates en racines très-amères, son repos en inquietudes \& ses joies en larmes» ${ }^{27}$. La resignación de la infeliz Princesa ante las iniquidades de la vida, así la evoca el propio narrador: "[...] Tu y verras le vice honoré, la vertu méprisée, l'impureté en crédit, la flatterie louée, la vanité estimée; tandis qu'une pauvre Dame souffre au coin d'un bois pour avoir voulu être innocente, $[. ..] »^{28}$.

25. Julián Marías (La mujer y su sombra, Madrid, Alianza edit., 1986) aporta un dato muy interesante que apoyaría esa visión de la mujer: el hecho de que históricamente sólo se habla de «hombres» en general, no de varones y mujeres, que la vida humana se realiza en dos formas, por supuesto inseparables, [...], op. cit., p. 52. Y añade: «La razón de esta ausencia [...] es que al pensamiento occidental ha propendido a un sustancialismo que siempre terminaba por tomar las cosas como modelo de realidad». La mujer ha estado siempre «ausente», su identidad nace al lado del varón.

26. Linnocence reconnue, op. cit., p. 277.

27. Ibidem, pp. 284-285.

28. Ibidem, p. 286. 
«Conformidad y paciencia»: virtudes enteramente cristianas. Pruebas fehacientes de estoicismo cristiano, las hallamos en muchos de los diálogos del texto. Cuando Genoveva interpela a Dios por qué razón la ha sumido en esa situación de desgracia, obtiene la siguiente respuesta de la divinidad: «[...] Decidme: ¿Qué pecados me han clavado en esta Cruz? ¿Acaso estáis vos más inocente, que yo, o mis males son más tolerables que los vuestros?» ${ }^{29}$. Así dice el texto francés ${ }^{30}:$ "Tu demandes quel crime t’a mise ici: dis-moi, quel péché m'a attaché à la Croix? es-tu plus innocente que moi? ou tes maux sont-ils plus grands que les miens?"

A lo largo del texto, Genoveva de Brabante tendrá que hacer acopio de "conformidad» y de enorme "paciencia», dos aspectos más de su carácter; ahora bien, esa "conformidad» y "paciencia» no serán un «motivo» (a la manera de decir de Thomson) sino más bien una actitud heredada del espíritu de la Contrarreforma.

Hay que recordar que el adaptador de la historia de Geneviève de Brabant, el padre René de Cerisiers pertenece a la Compañía de Jesús.. En un momento dado, cuando Genoveva se queja al ver su belleza perdida, debido a los rigores a los que se ve obligada a vivir, la reina de los Ángeles le previene de que esa belleza que poseía ha sido el origen de todos sus males : "[...], que la beldad ha causado la pérdida de la mitad del mundo [...]» ${ }^{31}$. La propia Genoveva se siente dolida por haber dicho estas palabras: «[...] quedó también corrida y confusa, por haver hecho ostentación, y estima de su pasada hermosura.» ${ }^{32}$. La verdadera paz se vislumbra en el más allá. Todas las durezas e ignominias de este mundo son premiadas en el más allá : «[...], porque las riquezas muchas veces son causa de perdición para los malos, y a los buenos dexa de enriquecer en este mundo, para después larga y liberalmente en el otro».

Huir de este mundo lleno de miserias. Cuando Genoveva alaba la vida que le ha deparado el Señor en la soledad más infinita y en la más injusta de las miserias, afirma que prefiere todo eso a la "Maison de mon mari» ${ }^{33}$ que no es otra cosa que «un esclavage volontaire, une honnête servitude, des chaînes qui, pour être dorées ne laissent pas que d'être fâcheuses \& insupportables». Algo sorprende notablemente: «la casa del marido»; finalmente la institución

29. Vida de Santa Genoveva, princesa de Brabante: traducida al español por el padre Cerisiers, op. cit., 108.

30. Linnocence reconnue, op. cit., p. 294.

31. Vida de Santa Genoveva, princesa de Brabante: traducida al español por el padre Cerisiers, op. cit., 116.

32. Ibidem, p.117.

33. Linnocence reconnue, op. cit., p. 298. 
matrimonial queda en segundo lugar. No hay más gloria que la de sufrir, penar según los designios del Señor. "Chaînes» dice Genoveva frente a la libertad del bosque, y sigue añadiendo "fâcheuses et insupportables».

No cabría ahí llevar a cabo una visión desde la óptica actual, y creer que se pretende arremeter contra la institución matrimonial. En las declaraciones de Genoveva anida la idea de ensalzar «la gloria de los cielos» frente a la vanidad terrenal.

Paulatinamente se ha llegado a configurar una "mujer-tipo», consagrada a la vida del martirio, "[...], \& sa patience se perfectionna jusqu’à ce point de regarder les souffrances comme des délices;» ${ }^{34}$. Podría hablarse incluso de un éxtasis del Cristianismo: "[...] pour mourir dans la joie d'une vie chargée des mérites de la patience» ${ }^{35}$. La misma idea se observa en otro fragmento: "[...], c'est ici le bouclier qui fera tomber tous les coups de l'adversité à vos pieds; c'est la clef qui ouvrira le Ciel à votre patience [...]» ${ }^{36}$.

El personaje de Geneviève aparece más firme a través de la narración; los continuos pesares que le tocan vivir fortalecen cada vez más su espíritu: "[...] de son pauvre lit aussi saine qu'elle étoit avant cette dernière maladie; à la voir lever, on ê̂t dit que c'était une résurrection qui se faisoit \& non pas une guérison.» ${ }^{37}$.

¿Qué duda cabe que la historia de Geneviève de Brabant se nos muestra como un verdadero catecismo? La "perfecta casada» debe observar la conducta que en todo momento no abandona Geneviève. Aunque la verdad está de su parte, no por ese motivo debe odiar a su marido (que es quien ha permitido todos los pesares que le acaecen), sino esperar de la «divina providencia» el consuelo a sus penas y un «más allá» que sabrá reconocer todas sus virtudes.

Ese tema no era extraño. En el mundo de los manuscritos encontramos ya interés sobre ese tipo de "historias». Así, en el Inventario general de Manuscritos de la Biblioteca Nacional, se delata el interés de los lectores de la Baja Edad Media hacia la "perfección» de las mujeres casadas.. De ahí que aparezca la obra De Claris Mulieribus de Boccaccio del siglo XIV.

II. Tablas comparativas: la edición francesa de Geneviève de Brabant y la edición española de Vida de Santa Genoveva, princesa de Brabante.

Se notan diferencias sustanciales entre una edición y otra. Se indican los cambios habidos en la edición española respecto de la francesa.

34. Linnocence reconnue, op. cit., p. 289.

35. Ibidem, p. 294.

36. Ibidem, p. 291.

37. Ibidem, p. 308. 


\section{Supresión de textos.-}

Edición francesa,

L'innocence reconnue.

En la edición francesa hay siempre un intento de ampliar el texto. Geneviève se acaba de casar con el Palatin. Las fiestas que se preparan para tal evento son suntuosas: "[...] Les danses, les bals, les tournois \& tous les autres exercices de galanteries furent les moindres passe temps de cette Fête» (op. cit., p. 248).

Se dice en la edición francesa, cuando la pobre Geneviève se halla presa en la torre de su palacio debido a las maquinaciones del pérfido Golo: «[...] C'est ainsi que la pauvre innocente soupiroit nuit \& tour sans espérer aucun soulagement que du Ciel; car d'en attendre des hommes, c'ê̂t été aider à s'abuser \& chercher des illusions» (op. cit., p. 268).

\section{Edición castellana,}

Vida de Santa Genoveva, princesa de Brabante.

En la edición castellana se ha omitido el fragmento. El traductor, que no es otro que el adaptador de la leyenda francesa de Geneviève de Brabant, el padre René de Ceriziers, «resume» el fragmento en "[...], en cuyas bodas no se omitió regocijo alguno. Pasando en silencio el exagerar la solemnidad de tan ilustres Príncipes, pasando que la juzgue el discreto, $[\ldots]$ » (op. cit., p. 15).

Este fragmento no existe en la edición castellana.
Dentro de ese mismo capítulo, donde se nos ofrece el sufrimiento de la infeliz protagonista se dice: "[...] Dieu gardera toujours la chasteté de ses Martyrs, je ne refuse pas d'en être; mais d'attendre que je te permette autre chose que de me tuer, c'est perdre ton temps \& tes peines» (op. cit., 268).
Este fragmento no existe en la edición castellana. 
Hay un cierto gusto por los discursos largos. Sifroy se entera finalmente de la inocencia de su esposa, una vez que ya la cree muerta. Dice:

"[...] Ah! Cruel Bourreau, n'étoit-ce pas assez de ruiner ma maison [...] Oh! que n'as tu cent vies pour expier l'horreur du crime! traitre! perfide! [...]” (op. cit., p. 309).

Aunque algunas veces ocurre lo contrario. En la edición francesa, Sifroy, muestra su sorpresa ante el hallazgo de esa pobre mujer en el bosque, de la que ignora que es su esposa: «[...] \& pourquoi elle sétoit retirée dans un désert si affreux» (op. cit., p. 312).

Cuando el descubrimiento del pez, que lleva en su buche el anillo que, una vez, Geneviève lanzó al río, el texto francés es escueto: "[...] d'une grandeur prodigieuse; mais la merveille fut qu'après l'avoir vuidé, on trouva dans son boyau une bague que Sifroy reconnut être celle que Geneviève avoit jettée dans la rivière. [...]” (op. cit., p. 316).
En la edición castellana se dice: «Los de aquella Republica enviaron luego un expreso con esta nueva al Palatino Sigifredo, que le causó el dolor y sentimiento, que permitió la perdida y muerte tan arrebatada de su querida e inocente esposa, consolándole, que murió libre del crimen que la imputaron» (Op. cit., p. 141).

La labor de síntesis que se ha efectuado en la edición castellana es bien clara.

En cambio, en la edición castellana, hay una predilección por los discursos más expansivos: «[...], haciendo brecha al alma de Sigifredo la memoria de su dulce esposa, preguntándola su nombre, patria y la razón de estar en aquella espantosa soledad» (op. cit., p. 148).

En la edición castellana se añade incluso un ejemplo: «[...], hallaron en el buche el anillo, que Genoveva arrojó (como arriba está dicho) en la Mosela. [...] No es este el primer prodigio que se ha visto, porque un Rey de Samarcia, haviendo arrojado en el mar una esmeralda, la hallaron debaxo de la lengua de un pez, que le fue seis días presentado. [...]» (op. cit., p. 159).

\section{Ampliaciones y variaciones.-}

Laedición francesa no ofrecela descripción presente en la edición castellana y prefiere que el personaje masculino dé rienda suelta a sus sentimientos ante la sorpresa de hallar a su mujer e hijo: "Combien de baisers pressés sur sa bouche \& sur ses joues! [...]” (op. cit., p. 314)
En la edición castellana, suelen ańadirse o ampliarse más elementos en una situación dada; algo que no aparece en la edición francesa; como el ejemplo aquél en que Sigifredo halla en el bosque a su mujer y a su hijo, «[...] y descubriendo un hombre, y un cavallo, que estaban cerca de ella, se puso en huida, temeroso de ver en aquella espesura lo que jamás en ella havia visto. Su madre lo llamó, diciendo que allí estaba su padre [...]» (op. cit., p. 154) 
Asimismo, la edición francesa tiende a ser lo más objetiva posible, el narrador se presenta en $3^{\text {a }}$ persona. Geneviève abandona el bosque: "la Caverne en devint plus sombre, l'eau sembloit murmurer de plus haut [...]; les oiseaux l'accompagnèrent jusqu'à la sortie du bois, marquant par le battement de leurs ailes, \& [...]»
Pero, en la misma situación, la edición castellana gusta de solazarse en la descripción de la gruta: «A Dios, Sagrada Gruta y dulce alvergue, que has velado mis males tanto tiempo [...]. Adios, frondosos Olmos, Hayas, Pinos y Fresnos, que haveis con vuestras ramas y Hojas compuesto un pabellón. [...] Quedaos con Dios, mis Paxarillos, que con vuestra armonía y dulce canto haveis a mis sentidos recreado, [...] Permita nuestro Dios preservar de Falcones, Azores y de lazos vuestra simple inocencia. Adios Leopardos, Ossos, Jabalíes, [...], que me han servido de dulce compañía en mi destierro.» (Op. cit., pp. 156-157).

\section{Pequeños cambios.-}

1). Cierta libertad en la traducción.-

En la edición francesa, la premonición del futuro que le aguarda a Geneviève: «[...] celui d'Eve dans un Paradis, il se terminera comme le sien dans une solitude." (Op. cit., p. 248)

2). Pequeños cambios en la exposición de las delicias del castillo donde viven los dos esposos.-

"; Le Château étoit entouré d'un Parc où il sembloit que le Printemps se retiroit avec les Zéphirs [...]. Quelque rigoureux que fût l'hiver, il ne touchoit point aux Oranges. [...] Ce fut dans ce lieu plein de délices \& tout semblable aux Palais enchantes des Romans, que Sifroy \& Geneviève menoient la plus douce \& la plus innocente vie de leur siècle." (Op. cit., p. 249).
La edición castellana usará de libertad en el momento de la traducción: «[...] en Paraíso, y terminándole en un desierto.» (Op. cit., p. 16)

En la edición castellana ha habido un verdadero cambio en la exposición de los hechos:

«Estaba situado este castillo casi a las margenes del Rio Mosella, que la naturaleza y el arte lo hacían muy deleytoso; cada una de sus Torres, cubiertas de pizarras, parecía de lexos una esfera, y todo junto, encantado edificio de Romanos. (Op. cit., p. 17). 
3). Tendencia a resumir fragmentos.-

Siffroy debe partir para la guerra y confía a su esposa a Golo. El discurso es largo: "[...] Ma fille, voici Golo à qui je laisse le soin de mes plaisirs; l'expérience que j'ai de sa fidelité me fait espérer que l'ennui de mon absence sera en quelque façon modéré [...]. Je ne vous dis autre chose à sa recommadation, sinon qu'après moi vous devez attendre plus de soulagement de lui que de personne au monde, [...]» (op. cit., p. 251).

En la edición francesa se dice: "[...] un grand nombre de Genettes, qui sont des petits animaux noirs mouchetés de taches rouges." (op. cit., p. 254).

4). Un «estilo» distinto para una sola cita.-

Geneviève habla del hijo que lleva en sus entrańas a sus enemigos: "[...] d'exposer trois personnes à une même mort.» (op. cit., p. 259).

En ciertos momentos, incluso puede aparecer una metáfora, que no se halla en la edición castellana:

"Petit Papillon, vous vous brûlerez, si vous ne vous éloignez de cette lumière, dont l'éclat ne vous sera pas moins funeste que celui d'une Comète.» (op. cit., p. 260).
En la edición castellana se resume notablemente:

«: aquí os dexo à Golo, espero en su fidelidad cuidará de vuestro regalo, y consuelo; y así os pido lo estimeis, por lo mucho que yo lo quiero.» (op. cit., p. 22).
En la edición castellana se ha resumido: «[...] una gran cantidad de ginetes». (op. cit., p. 28).

El texto castellano dice:

«[...] cuidad por lo menos, que el fruto (que creo llevar conmigo) esté fuera del peligro, que le amenaza la sepultura.» (op. cit., p. 36).
"Apártate, mariposa, no te llegues a las llamas, si no quieres precipitarte, y perderte.» (op. cit., p. 38). 


\section{Ediciones en español}

Y ya como punto final, el número de ediciones en español de Genoveva de Brabante. Se ha indagado en varias catalogaciones:

10) Catálogo Colectivo del Patrimonio Bibliográfico Español.-

2o) Biblioteca Nacional de España.-

30) Biblioteca de Catalunya.-

40) Palau i Dulcet, Antoni (1867-1954). Manual del librero hispano-americano: bibliografia general española e hispanoamericana desde la invención de la imprenta hasta nuestros tiempos, con el valor comercial de los impresos descritos.-

50) British Museum.-

$\left.6^{\circ}\right)$ Botrel, Jean-François, «Les historias de colportage: essai de catalogue d'une Bibliothèque Bleue espagnole (1840-1936)", en Les productions populaires en Espagne 1850-1920, Paris, Éditions du Centre Nacional de la Recherche Scientifique, 1986, págs. 25-62.

10) Catálogo Colectivo del Patrimonio Bibliográfico Español.-

1. Autor: Ceriziers, René de (1603-1662), trad.

Título: Vida de Santa Genoveva, princesa de Brabante / traducida en español por el Señor Cerisiers.

Publicación: en Madrid: en la Imprenta de Don Gabriel del Barrio...: a costa de Doña Francisca de Guzmán, vendese en su casa, en la Puerta del Sol, a la entrada de las Carretas, 1726.

Descripción: [10], 200p.; 8º.

Notas: El editor precede al lugar de edición

Sign.: []1, [calderón]4, A-M8, N4

Port. Con orla tip.

Front. Calc.: «R. Rouge Escpit.»

2. Autor: Ceriziers, René de (1603-1662).

Título: Vida de Santa Genoveva, Princesa de Brabante [ autor, René de Cerisiers ]; traducida en español por el Sr. Cerisiers.

Publicación: Madrid: [S. n.], 1865 (Imprenta de D. José M. Lezcano y Roldán).

Descripción: 135 p; $16 \mathrm{~cm}$.

3. Título: Vida de Santa Genoveva, princesa de Brabante / traducida en español por el sr. Cerisiers.

Publicación: Valladolid: [s. n.], 1856 (Imprenta de D. Dámaso Santaren).

Descripción: 128, [1] p. il.; $15 \mathrm{~cm}$.

4. Autor: Schmid, Cristoph von

Otros responsables: Imprenta Católica.

Título: Genoveva de Brabantel por Schmid; Traducción del Solitario de la Magdalena.

Publicación: Valencia: [ S. n.], 1876 (Imprenta Católica).

Descripción: 98, [2] p.; $21 \mathrm{~cm}$.

Serie: La Ilustración popular económica. Bteca. Moral.

Notas: Encabezamiento completado con Palau, XX, p. 243. 
5. Autor: Cremieux.

Otros responsables: Trefeu, Offenbach, mús.

Título: Genoveva de Brabante: zarzuela bufa en 3 actos Escrita en francés/ por Cremieux y Trefeu, música del maestro Offenbach; arreglada a la escena española por Rodino y Bardan.

Publicación: Madrid: [ s. n.], 1869 (José Rodríguez).

Descripción: 82 p.; $18 \mathrm{~cm}$.

3 ejemplares encontrados en Madrid:

1. Madrid. Ateneo de Madrid (encuadernado en pasta española).

2. Madrid. Idem (enc. hol.).

3. Madrid. Sociedad General de Autores y editores. Enc. hol. Falto de la cubierta original. Enc. en un vol. ficticio. Sobre el pie de imprenta de la portada banderilla en la que consta: Imprenta, librería y litografía del Diario de Córdoba.

6. Título: [Vida de Santa Genoveva, princesa de Bravante].

Publicación: [S. I.: S. n., S. a]

Descripción:+ 145p., $8^{\circ}$

Notas: Título tomado de cabecera de texto. Probablemente

del siglo XVIII. Enc. perg. Falto de portada.

7. Título: Relación histórica en que se refiere la peregrina y trágica vida de la penitente anacoreta, la princesa de Brabante Santa Genoveva, sacada de la verídica historia de la misma santa.

Publicación: Madrid: Despacho de Marés y Compañía, [s. a.]. Descripción: 8p. : il. ; $23 \mathrm{~cm}$.

Notas: J. M. Marés y Compañía ejerce ca. 1867-1874.

Enc. pasta valenciana. En la $1^{\mathrm{a}} \mathrm{p}$. consta el $\mathrm{n}^{\circ} 18$.

8. Otros responsables: Laborda, Agusrí, imp.

Título: Primera parte en que se refiere la Peregrina Historia y

Trágica vida de la Penitente Anacoreta la Princesa de

Brabante Santa Genoveva: sacada de la vida...

Publicación: en Valencia: en la imprenta de Agustín

Laborda..., [s. a.].

Descripción: en Valencia: [4] p.: il.; $4^{\circ}$

Todo indica que podía muy bien tratarse de un "pliego suelto».

9. Otros responsables: Granja, Cosme, imp.

Título: Nuevo: en que se refiere la peregrina historia y trágica vida de la penitente Anacoreta, la princesa Brabante Santa Genoveva..., primera [segunda] parte

Publicación: en Valencia: en la imprenta de Cosme Granja..., [s.a] 
Descripción: [8] p. ; 4º.

Notas: Port. con grab. xil.

Pie de imprenta tomado de colofón

Texto a dos col.

Sig.: [] 4

10. Otros responsables: Laborda, Agustín, imp.

Título: Segunda parte en que se da fin a la preregrina historia de la invencible princesa de Brabante Santa Genoveva

Publicación: Se hallará en Valencia: en la Imprenta de Agustín Laborda..., [s.a.]

Descripción: [4] p.; $4^{\circ}$

Notas: Fechas en activo de Agustín Laborda

Sign.: [] 2

Grab. xiI. en p. [1]

Podría muy bien tratarse de un «pliego suelto».

11. Otros responsables: Llorens, imp.

Título: Historia de la virtuosa y penitente Santa Genoveva, princesa de Brabante: escrita en verso

Publicación: Barcelona: [s.n.], [s.a.] (imp. de Llorens)

Descripción: 24p.: il.; $21 \mathrm{~cm}$

Serie: Galería histórica moderna

Notas: Fecha de impresión ca. 1880 a partir de las características del doc.

12. Otros responsables: Vidal, Juan Bautista, ed.

Título: Historia de la virtuosa y penitente Santa Genoveva, princesa de Brabante

Publicación: Reus: Librería de Juan Bautista Vidal, [s.a.]

Descripción: 24p.; $21 \mathrm{~cm}$

Notas: Junto con $1 \mathrm{~h}$. De propaganda editorial

Fecha de impresión ca. 1880, a partir de las

características del doc.

13. Otros responsables: Serra, Juan, imp. Centené, Juan, imp.

Título: Vida de Santa Genoveva, princesa de Brabante / traducida en español por el señor

\section{Cerisiers}

Publicación: Barcelona: por Juan Centené y Juan Serra, 1794

Descripción: 140 p.; $8^{\circ}(16 \mathrm{~cm})$

Notas: Existe una ed. muy similar, pero de 136 p., con pie de imprenta: Barcelona: por Juan Serra y Centené..., [1794 o post.]

14. Otros responsables: Ceriziers, René de (1603-1662), trad.

Martín, Manuel, imp.

Título: Vida de Santa Genoveva princesa de Brabante / traducida por el Señor Cerisiers

Publicación: en Madrid: en la Imprenta y Librería de D. Manuel Martin..., 1777

Descripción: 145, [7] p.; $8^{\circ}$

Notas: Sign.: A-18, K4 
15. Autor: Schmid, Christoph von (1768-1854)

Título: Genoveva de Brabante / por Cristóbal Schmid

Publicación: Barcelona: Librería de Estevan Pujal..., se hallará también en la tienda de libros de Ramón Pujal, 1859

Descripción: 223 p.; $12 \mathrm{~cm}$

16. Otros responsables: Ceriziers, René de (1603-1662), trad.

Título: Vida de Santa Genoveva princesa de Brabante / traducida en español por el señor Cerisiers

Publicación: Valladolid : [s.n.], 1857 (Imprenta de D. José María Lezcano y Roldán)

Descripción: 131 p. ; $16 \mathrm{~cm}$

17. Otros responsables: Ceriziers, René de (1603-1662), trad.

Título: Vida de Santa Genoveva princesa de Brabante / traducida en español por el Señor Cerisiers.

Publicación: Valladolid: Imprenta y Librería de Roldan, á cargo de D. Calixto Yepes, 1863.

Descripción: [4], 131 p. ; $15 \mathrm{~cm}$

18. Autor: Cruz de Zapirain, Juan

Otros responsables: Lecuona, Manuel, pr., trad.

Título: Genoveva de Brabante / por el «bertsolari» Juan Cruz de Zapirain; Manuel de Lecuona

Publicación: [Vitoria] : Trabajos del laboratorio de Euzco-Folklore, [s.a.]

Descripción: 68 p.: [1] fot. N. ; $17 \mathrm{~cm}$

Notas: Fecha de cabecera y lugar de publicación tomados del prólogo, 1929

Port. con grab.

19. Otros responsables: Santarén, F., ed., Cerisiers, trad.

Título: Vida de Santa Genoveva, princesa de Brabante / traducida en español por el señor

Cerisiers

Publicación: Valladolid : Imp., Lib. y Almacén de papel de F. Santarén, 1891

Descripción: 124, [ 1 ] p. ; $15 \mathrm{~cm}$

20. Autor: Schmid, Cristoph von (1768-1854)

Título: Jenoveva de Brabante / por Cristóbal Schmid

Publicación: Barcelona : Libr. de Estevan Pujal, 1850

Descripción: 224p., [ 1 ] h. de lam. : il. ; $13 \mathrm{~cm}$

Notas: Tít. en la portada adicional: Genoveva de Brabante

Estampa calcográfica

21. Otros responsables: Ceriziers, René de (1603-1662), trad.

Pastor, Julian, Hijos de, ed.

Título: Vida de santa Genoveva princesa de Brabante / traducida en español por el Sr.

Cerisiers

Publicación: Valladolid: Imprenta y Librería de Hijos de J. Pastor, 1877

Descripción: 111, [ 1 ] p. : il ; 16 cm 
22. Título: Historia de la virtuosa y penitente Santa Genoveva, princesa de Brabante Publicación: Madrid : Despacho al por mayor, Juanelo 19 : Despacho al por menor, Duque de Alba, 9, 1881

Descripción: 24 p. ; $21 \mathrm{~cm}$

23. Autor: Cerisiers, René de (1603-1662)

Título uniforme: Innocence reconnue. Español

Título: Vida de Santa Genoveva: princesa de Brabante : traducida en español / por el señor Cerisiers

Publicación: Barcelona : [ s.n. ], 1848 (Impr. de José Piferrer)

Descripción: 147 p. ; $15 \mathrm{~cm}$

24. Otros responsables: Cerisiers, René de, trad.

Título: Vida de Santa Genoveva, Princesa de Brabante / traducida en español por el Señor Cerisiers

Publicación: Valladolid: [ s.n. ], 1813 (Imprenta de Roldán)

Descripción: 150, [ 1 ] p., [ 1 ] en bl.; $15 \mathrm{~cm}$

Notas: Signaturizado

25. Otros responsables: Serra y Centené, Juan, imp.

Título: Vida de Santa Genoveva, princesa de Brabante / traducida en español por el señor Cerisiers

Publicación: Barcelona : por Juan Serra y Centené..., [ s.a. ]

Descripción: 136 p. ; $8^{\circ}(16 \mathrm{~cm})$

Notas: Fecha aprox., 1794 o post., deducida de una ed. muy similar, pero de 140 p. y con pie de imp.: Barcelona : por Juan Centené y Juan Serra..., 1794

Reclamos

Alguna ornamentación

26. Título: Historia de la virtuosa y penitente santa Genoveva:

Princesa de Brabante

Publicación: Reus : La Fleca, [...]

Descripción: 24 p : il ; $21 \mathrm{~cm}$

Serie: Nueva galería histórica

Notas: Según Cat. Col. de Cataluña la fecha de publicación es 1877

27. Título: Historia de la virtuosa y penitente Santa Genoveva, princesa de Brabante

Publicación: Madrid : [s. n.], 1851 (Imprenta de José María Marés)

Descripción: 24 p. : il. ; $22 \mathrm{~cm}$

Notas: Il. Xil. en cabecera de port.

28. Autor: Cerisiers, René de

Otros responsables: Piferrer, Viuda de, imp. Sellent, Juan, ed.

Título: Vida de Santa Genoveva, princesa de Brabante / traducida al español por el señor Cerisiers

Publicación: Barcelona : en la Oficina [sic] de la Viuda Piferrer ... : véndese en su Librería administrada por Juan Sellent, [s.a.] 
Descripción: 173 p., [3] en bl. ; $8^{\circ}$

Notas: Según Gutierrez del Caño, la viuda de Piferrer ejerce entre 1775 y 1792

Sign.: A-L8

29. Título: Vida de Santa Genoveva Princesa de Brabante /

traducida en español por el Señor Cerisiers

Publicación: Valladolid : Imprenta, librería y almacen de papel de Fernando Santaren

Descripción: 126 p. : il. ; $16 \mathrm{~cm}$

Notas: Grab. xil. de Santa Genoveva en el verso de la port.

$\left.2^{\circ}\right)$ Biblioteca Nacional de España. Libros antiguos hasta 1830.-

1) Título: Historia de la vida de Santa Genoveva, princesa de Brabante y del conde Palatino Sigifriedo su esposo.

Publicación: Sevilla; Imp. de la Viuda de Vázquez y Compañía, (S. a.: S. XIX). 48 p.; grab.; $22 \mathrm{~cm}$.

2) Título: Santa Genoveva; Romance en que se refiere la Peregrina historia y tragica vida de esta Penitente Anacoreta, Princesa de Brabante, sacado de la vida, que anda impresa de la misma Santa.

Publicación (Córdoba: en la Imp. de D. Rafael García Rodríguez), (S. a.: S. XIX). 4h.; grab; $4^{\circ}(21 \mathrm{~cm})$.

3) Autor: Cerisiers, René de (1603-1662).

Título: Vida de Santa Genoveva Princesa de Brabante / traducida en Español; por el sr. Cerisiers.

Publicación: Madrid: Gabriel del Barrio, 1726. 4h.+ 199 p; $8^{\circ}$

4) Autor: Cerisiers, René de (1603-1662).

Título: Vida de Santa Genoveva, princesa de Brabante / traducida en español por el sr. Cerisiers...

Publicación: Valencia: Benito Monfort, 1768.

Sign A $2+188$ p. ; $8^{\circ}(15 \mathrm{~cm})$.

3o) Biblioteca de Catalunya.-

1) Título: Historia de la virtuosa y penitente Santa Genoveva: princesa de Brabante.

Publicación: Reus; La Fleca, (1877?)

$24 \mathrm{p}$ : il; $21 \mathrm{~cm}$.

Col. Nueva Galería histórica

Contenido: Incipit: «En una de las provincias de la antigua Galia...

Grabado xilogr. en la cubierta de papel col. verde y en la portada. Texto en prosa.

2) Autor: Schmid, Christoph von, 1768-1854

Título: Jenoveva de Brabante / por Cristóbal Schmid.

Publicación: Barcelona, Librería de Estevan Puyal, 1850.

224 p., [ 1 ] f. de lám: il.; $13 \mathrm{~cm}$.

Estampa calcográfica. 
3) Historia de la virtuosa y penitente Santa Genoveva, princesa de Brabante.

Madrid; Despacho al por mayor, Juanelo 19:

Despacho al por menor, Duque de Alba, 9, 1881

24p. ; $21 \mathrm{~cm}$.

4) Autor: Schmid, Christoph von, 1768-1854

Título: Genoveva de Brabante / de Cristóbal Schmid; traducido por D. José Arroyo y Almela. $2^{\mathrm{a}}$ ed.

Publicación: Barcelona, Juan Roca y Bros, 1866, i.e. 1867.

(Barcelona: Imp. de «El Porvenir de la V. de Bassas, 1867)

Descripción [2], 188, [2] p., [2] f. de lám. : il; 13 cm.

Col. Bteca. moral-creativa ilustrada, 4.

5) Autor: Schmid, Cristoph von, 1768-1854

Título: Genoveva de Brabante / por Cristóbal Schmid; versión española y prólogo por Pedro Umbert.

Publicación: Barcelona, Impr. de Henrich y Comp., (1910).

Descripción: 140, [4] p. : il. ; 26 cm.

(Tela) sin paginar

Incluye prólogo del trad.

Año probable de impresión obtenido por licencia eclesiástica.

Monograma con la leyenda «Ex fumo dare lucem» en la cubierta posterior.

6) Autor: Cerisiers, René de, 1603-1662.

[ Innocence reconnue. Castellano ]

Título: Vida de Santa Genoveva; princesa de Brabante : traducida en español / por el Sr.

Cerisiers.

Barcelona; Impr. de José Piferrer, 1848.

147 p. ; $15 \mathrm{~cm}$.

7) Autor (Serra, José Ma. S., 1873-1951)

Título: Genoveva de Brabante : (La dona santa): drama

Històric en 6 actes i en vers / de José Ma S. Serra.

Barcelona: Vila, Aleu \& Domingo impressors, (1928 o post.)

34 p. $25 \mathrm{~cm}$.

«Estrenat en el Teatre Vigatà en el mes de Febrer de 1928».

8) Historia de la virtuosa y penitente Santa Genoveva, princesa de Brabante. Madrid : Impr. de Marés y Compañía, 1865. 23 p. Incipit: «En una de las provincias de la antigua Galia...”

Caja: $182 \times 112 \mathrm{~mm}$, texto a 1 columna. Estampa de «Pérez».

9) Historia de la virtuosa y penitente Santa Genoveva princesa de Brabante.

Madrid: Despacho, calle de la Bola, no 11, (185-¿?)

24 p. Incipit: «En una de las provincias...»

Fecha deducida de la época de trabajo del impresor.

Caja: $178 \times 114 \mathrm{~mm}$, texto a 1 columna.

Estampa alusiva al romance. 


\section{BULLETIN HISPANIQUE}

10) Relación histórica en que se refiere la peregrina y trágica vida de la penitente anacoreta, la princesa de Brabante Santa Genoveva; sacada de la verídica historia de la misma santa. Madrid, Impr. de Marés y Compañía, (1850 o post) 8p. Incluye: Segunda parte en que se da fin a la peregrina historia de la virtuosa princesa de Brabante Santa Genoveva. (p. 5). Caja: 170x110 mm., texto a 2 columnas

11) Relación histórica en que se refiere la peregrina y trágica vida de la penitente anacoreta, la princesa de Brabante Santa Genoveva; sacada de la verídica historia de la misma santa. Madrid. Impr. de D. José Marés, 1848. 8p. Incluye: Segunda parte en que se da fin a la peregrina historia de la virtuosa princesa de Brabante Santa Genoveva (p.5)

Incipit: «No canto fingidos hechos / ni invento falsas novelas.

Caja: $165 \times 112 \mathrm{~mm}$, texto a dos columnas.

Estampa.

12) Autor: Schmid, Cristoph von

Título: Genoveva de Brabante; canónigo J. Cristóbal Schmid; versión española de H. C. Granch; ilustraciones de

Julio Vivas. Barcelona, Maucci, (19...?) 158p. : il.; $18 \mathrm{~cm}$.

13) Autor: Schmid, Cristoph von

Título: Genoveva de Brabante; canónigo J. Cristóbal Schmid; [ traducción de Ma Dolors García-Lomas; portada e ilustraciones: Fariñas). Barcelona: Mateu, (195-¿̨) 255 p.: il. Col. juvenil cadete, 58 .

14) Historia de la virtuosa y penitente Santa Genoveva: princesa de Brabante; escrita en verso. Barcelona: Imp. Sucesor de Vda. de A. Llorens, (19...?) 24 p. ; 21, 5 cm. Col. Galería histórica moderna.

4º) Palau i Dulcet, Antoni (1867- 1954). Manual del librero hispanoamericano: bibliografia general española e hispanoamericana desde la invención de la imprenta hasta nuestros tiempos,...» Barcelona, Librería Palau, 2a edición corregida y aumentada,(19481977), 1967, vol. XIX, pp. 423-424

1) Historia de la vida de...Princesa de Brabante, por el padre Cerisiers de la Compañía de Jesús, Nueva edición dividida en capítulos, corregida y puesta en buen orden por Francisco Sobrino. En Bruselas en casa de Fc. Foppens. 1717, $8^{\circ} 7$ h. 205 p. 1 h. blanca.

2) Vida de...Princesa de Brabante, Traducida en espańol por el Sr. Cerisiers. Madrid, 1758, $12^{\circ}$.

3) Idem. Barcelona, por la Viuda de Piferrer, véndese en la Librería administrada por Juan Sellent (1780), 8. $156 \mathrm{p}$.

4) Vida de....Trad. en español por el Sr. Cerisiers. Barcelona. Por Raimundo Altés, viuda, en la Librería, 1785. Véndese en casa de Juan Manuel librero. Bajada de la Cárcel, 8. ${ }^{\circ}$ $148 \mathrm{p}$. 
5) Vida de... Princesa de Brabante. Trad. Por el señor Cerisiers. Buenos Aires, 1793, 4. ${ }^{\circ}$, $4 \mathrm{p}$.

6) Vida de...Princesa de Brabante. Trad. en español por el Señor Cerisiers. Barcelona, Viuda de Piferrer, véndese en su librería administrada por Juan Sellent (179.) $18 .^{\circ} 173 \mathrm{p}$.

7) Vida de...Princesa de Brabante, traducida en español por el Sr. Cerisiers. Madrid, Vda. de Barco López, MDCCCXXI (1821), 8. 145 p. 3 h.

En la propia catalogación de Palau i Dulcet se hace referencia a esas ediciones a las que se denomina «ediciones populares de esta especie de novela caballeresca» (Op. cit., p. 423):

1) Historia de la vida de...Princesa de Brabante y del Conde Palatino Sigifredo, su esposo Córdoba, Don Rafael García Rodríguez, $4 .^{\circ} 71$ páginas, grabs. en madera; (siglo XVIII) $4 .{ }^{\circ} 8$ págs.

2) Primera parte en que se refiere la peregrina historia y tragica Vida de la Penitente Anacoreta la Princesa de Brabante..., Sacada de la vida, que anda impresa...Segunda Parte..., Barcelona, Juan Foros (principios del siglo XIX), $4 .^{\circ} 4 \mathrm{~h}$. gris.

3) Vida de...Princesa de Brabante.B., Viuda de Piferrer (1830), 8. ${ }^{\circ}$ pergamino, 156 págs.

4) Vida de...Princesa de Brabante. Traducida por el Sr. Cerisiers. B., José Piferrer, 1848, 8º.

5) Idem. Barcelona, $8 .^{\circ} 13$ p. 40 pts. Central. 1960

6) Santa Genoveva de Bravante. Vida. Madrid, 1865, $12 .^{\circ}$

7) Genoveva...Paris, A. Fonby y Roger, edt. 1879, 16 lam.

8) Santa Genoveva. Romance...sacado de la vida que anda impresa de la misma Santa (al fin:) Con licencia. En Córdoba en la Imp. de D. Rafael Garcia Rodríguez. Calle de la Librería (principio XIX), 2 vols. $4 .^{\circ} 4 \mathrm{~h}$.

9) Genoveva de Brabante. Historia de la virtuosa penitente Santa Genoveva, princesa de Brabante. Manresa, Soc. Editorial Manresana, 1190, 8. 64 p. en verso.

Aunque se alude al padre Cerisiers, como traductor material del texto francés de Geneviève de Brabant, no por ello debe obviarse a Cristophe Schmid, ampliamente citado en varias de las catalogaciones que contienen las ediciones de Genoveva de Brabante. Así encontramos una edición en la catalogación de Palau i Dulcet (op. cit., 1968, vol. XX, p. 243):

Genoveva... Madrid, Imp. y casa de la Unión Comercial, 1844, 32. (Obras del Canónigo Schmid) (8 reales). 
50) British Museum = British Museum Catalogue of Printed Books,

Photoligraphic Edition to 1955, 236 vols., London 1931-1966.

1) Historia de... Santa Genoveva, etc. Madrid, 1857. $4^{\circ}$.

2) Historia de...Santa Genoveva, etc. pp. 24. Madrid, 1879. 4º.

3) Primera (-segunda) parte, en que se refiere la peregrina historia y trágica vida de la penitente Anacoreta la Princesa de Bravante Santa Genoveva, etc. (En verso). Madrid, 1764. 4. $^{\circ}$.

4) Idem [1820?] 4. ${ }^{\circ}$.

5) Relación histórica, en que se refiere la... trágica vida de la ...princesa de Brabante, Santa Genoveva... Primera (segunda) parte. (En verso) pp. 8. Madrid, 1846, $4^{\circ}$.

6) Idem. Madrid, 1858. 4. ${ }^{\circ}$.

7) Relación histórica, en que se refiere la...vida...de...Santa Genoveva, etc. (En verso.) pp. 8. [1870?]

6a) Botrel, Jean-François, «Les historias de colportage: essai de catalogue d'une Bibliothèque Bleue espagnole (1840-1936)", en Les productions populaires en Espagne 1850-1920, op. cit.

Barcelona.-

1) Santa Genoveva de Brabante. Attesté dans la liste de 141 Historias que se venden en la misma casa, soit la Papelería del Sucesor de Antonio Bosch, publiée dans El Hijo pródigo. Novelita amena e instructiva basada en la parábola de nuestro Señor Jesuscristo y consignada en los Santos Evangelios, por Antonio Faura (Barcelona, Se halla de venta en la Papelería del Sucesor de Antonio Bosch, Calle del Bou de la Plaza Nueva, num. 13, 1876)

2) Idem. Attesté dans la liste de 28 Historias publiée dans Historia del bandido Corazón de Hierro o Julia y Diana las victimas del amor (Barcelona, Imps. de Antonio Llorens, Palma de Santa Catalina, 6, s.d. (Galería Histórica Moderna).

3) Idem. Attesté dans la liste de 28 Historias publiée dans Historia de la vida y hechos de Don Juan Tenorio (Barcelona : Imps. de Cristina segura, Vda. de A. LLorens, Palma de Sta. Catalina, 6, s.d. (Galería Histórica Moderna).

4) Idem. Attesté dans la liste de 28 Historias publiée dans Historia de la hermosa Atala o La Pastora del Bosque (Barcelona : Imps. Hospital, 19 «El Abánico») (le propiétaire en est Luis Raynaud, Suc. de Vda. de A. Llorens).

5) Idem. Attesté dans la liste de 125 Historias publiée par Sucesores de A. Bosch.

Madrid.-

1) Idem. Attesté dans de 62 Historias que se hallan en el mismo despacho, soit celui de José M. Marés publiée dans Historia del esforzado Clamades y la hermosa Clarmonda o sea El caballo de Madera. (Madrid : 1858. Imprenta a cargo de José M. Marés. Plazuela de la Cebada num. 96.).

2) Idem. Attesté dans la liste de 88 Historias que se hallan en el mismo despacho, soit celui de Manuel Minuesa, publiée dans Historia de Blanca de Navarra (Madrid, Juanelo, 19, 1879). 
3) Idem. Miquel Server (tel. 651), 1891.

4) Idem. Sucesores de Hernando, 1908-1924.

5) Idem. Biblioteca Moderna, (Madrid, Antigua Imprenta Universal calle de Cabestreros, núm. 5.). 1950.

Madrid-Barcelona.-

1) Idem. Madrid. Hernando. Barcelona. Bou de la Plaza Nueva, 13.

Palma.-

1) Idem. Attesté dans la liste de 106 Historias publiée dans le Sainete núm. 184 dont il est dit: «Se halla de venta en Palma, tienda de M. Borrás, calle del Sindicato número 139» (Biblioteca Bergnes de las Casas, Barcelona).

2) Idem. Attesté dans la liste de 112 Historias de 2,3,4 y 5 pliegos publiée dans le Sainete núm. 145 dont il est dit: «Se halla de venta en Palma, tienda de M. Borrás, calle del Sindicato número 139 (Biblioteca Bergnes de las Casas, Barcelona). También se halla en la tienda de M. Borrás, s.a.

Reus.-

1) Idem. Attesté dans la liste de 104 Historias que se hallan en venta en la Librería «La Fleca» de Vda. de Juan Grau Gené (Reus) publiée dans Historia del esforzado Clamades y la hermosa Clarmonda o sea El caballo de madera (s.d.) (Instituto Municipal de Historia, Barcelone).

2) Idem. Attesté dans la liste de 108 Historias que se hallan en venta à la Librería de Joan Grau y Gené, Carrer del metge Fortuna, número 3, publiée dans Historia o danza dramática de la aparició de la Verge de Misericordia, por F. T. Y P. Reus, 1881 (Nueva Galería Histórica) (Instituto Municipal de Historia, Barcelone).

3) Idem. Attesté dans la liste de 142 Historias que se hallan en el...despacho de Juan Ba Vidal (arrabal alto de Jesús, núm. 5, Reus) publiée dans Historia del esforzado caballero Pierres de Provenza y la hermosa Magalona (s.d.) (Instituto Municipal de Historia, Barcelone).

\section{Bibliografía}

Baranda, Nieves, ed., Historias caballerescas del siglo XVI, 2 vols., Madrid, Turner, 1995.

Baudoux-Spinette, Alberte, "Boccace et les folkloristes» in Il Boccaccio nelle culture e letteratura nazionali, a cura de Fco. Mazzoni. Firenze, Leo S. Olschki editore, 1978 (pp. 607-625).

Boccaccio, Decameron, a cura di Vittore Branca. Milano, Oscar, Mondadori, 2005; Classici, 146. 
Bollème, Geneviève, Le peuple par écrit. Préface de Jacques Le Goff. Paris, éditions du Seuil, 1986.

Bollème, Geneviève - Andries, Lise, La Bibliothèque Bleue. Littérature de colportage. Paris, éditions Robert Laffont, 2003.

Botrel, Jean-François, «Les historias de colportage: essai de catalogue d'une Bibliothèque Bleue espagnole (1840-1936)", in Les productions populaires en Espagne (1850-1920), Paris, Éditions du Centre Nacional de la Recherche Scientifique, 1986, pp. 25-62.

Catalán, Diego, Arte poética del romancero oral. Parte $1^{a}$. Los Textos abiertos de creación colectiva. Madrid, Siglo XXI de España Editores S. A. $1^{\text {a }}$ ed. 1997.

Delcourt, Thierry et Parinet, Élisabeth, La Bibliothèque Bleue et les littératures de colportage. Actes du colloque organisé par la Bibliothèque municipale à vocation régionale de Troyes en collaboration avec l'École nationale des chartes (Troyes, 1213 novembre 1999). Paris, École des Chartes. Troyes. La maison du Boulanger, 2000.

Delpech, François, "Como puerca en cenegal: remarques sur quelques naissances insolites dans les légendes généalogiques ibériques» in La condición en la Edad Media. Actas del coloquio celebrado en la Casa de Velázquez, del 5 al 7 de noviembre de 1984, coord. Y. R. Fonquerne y A. Esteban. Madrid, Universidad Complutense, 1986, pp. 343-370.

Geneviève de Brabant. L'innocence reconnue. Histoire de Geneviève de Brabant, escrita por el padre René de Ceriziers, in Geneviève Bollème, La Bibliothèque Bleue. La littérature populaire en France du XVII au XIXe siècle. Paris, Julliard-Gallimard, coll. "Archives», 1971, (2a ed. 1980); pp. 238-336.

Genoveva de Brabante. Vida de Sta. Genoveva, princesa de Brabante: traducida en español por el sr. Cerisiers. Madrid, por Antonio Pérez de Soto...: a costa de D. Pedro Joseph Alonso y Padilla..., 1760; 200p. $8^{\circ} 14 \mathrm{~cm}$.

Lacarra, Ma Jesús, Cuento y novela corta en España. I Edad Media. Prólogo general de Maxime Chevalier, Barcelona, Crítica, 1999.

- «Los paradigmas de hombre y de mujer en la literatura épico legendaria medieval castellana» in Estudios históricos y literarios sobre la mujer medieval, Málaga; Diputación, 1990, 7-34.

- «La mujer ejemplar en 3 textos épicos castellanos", en "Cuadernos de Investigación Filológica», XV (1988): 5-20.

Marías, Julián, La mujer y su sombra. Madrid, Alianza edit., 1986.

Pedrosa, José Manuel, Las dos sirenas y otros estudios de literatura tradicional, Madrid, Siglo XXI de España Editores, S.A. 1995.

Pisan, Christine de, La cité des dames, Paris, Stock / Moyen Âge, 1986.

Vincent, Bernard, "Lisants et non lisants des royaumes de Grenade et de Valence à la fin du XVI ${ }^{\mathrm{e}}$ siècle», in De l'alphabétisation aux circuits du livre en Espagne aux XVI'-XVII siècles, pp. 95-104. Toulouse, Centre Regional de Publication de Toulouse, ed. du CNRS, 1987. 